PII S0271-5317(97)00068-7

\title{
EFFECTS OF DIETARY FRYING OIL ON LIPIDS AND ANTI-CARDIOLIPIN ANTIBODY LEVELS IN AUTOIMMUNE-PRONE NZBXNZW F1 MICE
}

\author{
Bi-Fong Lin*, Ph.D. and Su-Jen Jeng, M.S. \\ Laboratory of Nutritional Chemistry, Department of Agricultural Chemistry, College of Agriculture, \\ National Taiwan University, Taipei, Taiwan 10764, Republic of China
}

\begin{abstract}
Two groups of NZB/W F1 mice were fed with diets containing $20 \%$ fresh and frying oils respectively. Serum levels of lipids, and anti-cardiolipin antibodies were followed regularly. The mice were sacrificed five months after feeding the experimental diets, the data showed: 1) body weight of mice fed frying oil was lower compared to that of fresh oil group; 2 ) relative tissue weight of mice fed frying oil were significantly higher compared to that of fresh oil group $(p<0.05) ; 3$ ) lower serum triglyceride level and higher cholesterol level were noted in mice fed with frying oil compared to those of fresh oil group; 4) both hepatic triglyceride and phospholipid levels were significantly lower in mice fed with frying oil; 5) IgG anticardiolipin antibody was found to be higher in mice fed dietary frying oil compared to that of mice fed fresh oil; 6) microsomal cytochrome P-450 content was significantly higher in mice fed frying oil compared to that of the fresh oil group; 7) higher serum estrogen levels were noted in mice fed with frying oil compared to those of fresh oil group. The data demonstrated dietary oil did affect lipid and anticardiolipin antibody levels in autoimmune mice.

O 1997 Elsevier Science Inc.
\end{abstract}

Key Words: Systemic lupus erythematosus, Dietary frying oil, Anti-cardiolipin antibody, Estradiol, NZBxNZW F1 mice

\section{INTRODUCTION}

A previous study has shown that mice fed with high fat diet developed more severe disease and had a shorter life span (1). Antibodies to cardiolipin in systemic lupus erythematosus (SLE) patients were found to be closely related to antiphospholipid syndrome which includes venous and arterial thrombosis, thrombocytopenia and recurrent fetal loss $(2,3)$. However, the effect of dietary frying oil on the production of anti-cardiolipin antibody and the pathogenesis of SLE have still not been well defined. Dietary frying oil might affect the degree of lipid oxidation and, subsequently, certain enzyme activity $(4,5)$. Dietary frying oil has been documented to influence the serum level of

\footnotetext{
*Corresponding Author : Dr. Bi-Fong Lin, Laboratory of Nutritional Chemistry, Department of Agricultural Chemistry, College of Agriculture, National Taiwan University. No.1, Sec. 4, Roosevelt Road, Taipei 10764, Taiwan, Republic of China.
} 
triglyceride, cholesterol and hepatic cytochrome P-450 activity (6). This study further investigated the effect of frying oil on scrum lcvels of cholesterol, triglyceride, phospholipid and immune response, including anti-cardiolipin antibody levels.

\section{MATERIALS AND METHODS}

Experimental animals. Four-week-old female NZBxNZW F1 mice were purchased from Charles River Japan (Tokyo, Japan) and maintained in the Department of Agricultural Chemistry at National Taiwan University College of Agriculture. Each group was comprised of 12 mice.

Preparation of oxidized frying oil and diets. The preparation and characterization of oxidized frying oil was similar to that described previously (6).Soybean oil (President Co., Tainan, Taiwan) purchased from a local supermarket was subjected to the frying process. The fresh oil diet was prepared and fatty acid composition was described previously $(1,7)$. The fatty acid contents of frying oil diet decreased $60 \sim 70 \%$ after frying process (8). The diet was fed ad libitum. The mice were fed the experimental diet starting from 2 months of age and sacrificed at 7 months of age. The mice were weighed twice a week, and food consumption was measured every two to three days.

Serum and liver triglyceride, cholesterol and phospholipid level. Mice were bled retroorbitally every month, with serum collected for determination of serum triglyceride, cholesterol, phospholipid, and anti-cardiolipin antibodies. Serum triglyceride, cholesterol and phospholipid levels were measured by colorimetric procedure $(7,8)$. The assay kits were purchased from Randox Laboratories Limited (N. Ireland, UK).

Determination of anti-cardiolipin antibodies. Serum anti-cardiolipin antibodies levels were determined using ELISA as that described previously (8). Serum sample (50-fold dilution for IgG and 100 -fold for IgM assay) to be determined were added and incubated for $2 \mathrm{hr}$ at room temperature. Serum of SLE patients were used as positive controls; procedures were the same except for secondary antibodies. All the values were assayed in triplicate and obtained by subtracting the non-specific binding of each sample.

Cytochrome P-450 activity of liver tissues. Livers from sacrificed mice were homogenized and microsomes were isolated. Cytochrome P-450 content was determined according to the method of Omura and Sato (10).

Serum estrogen level. Serum estradiol level of mice fed with fresh or frying oil was determined with ELISA kit (Cayman Co., Ann Arbor, MI).

Statistical analysis. Two-sided non-paired Student's t test of the SAS program system (SAS/STAT Version 6, SAS Institute Inc., Cary, NC) was used to analyze the data from this study.

\section{RESULTS}

Food intake, growth and tissue weights. The food intake after five months of feeding was not significantly different between the fresh oil group and the oxidized frying oil group. However, he body weight of the frying oil group $(36.8 \pm 5.2 \mathrm{~g})$ was significantly lower than that of the fresh oil group (48.2 $\pm 2.5 \mathrm{~g}$ ), which might be due to the lower digestibility of fat (6). The data suggested 
that the both absolute and relative weights of liver $(7.53 \pm 0.22 \%$ vs. $3.53 \pm 0.13 \%, P<0.05)$, kidney $(1.07 \pm 0.03 \%$ vs. $0.88 \pm 0.04 \%, P<0.05)$, brain $(1.23 \pm 0.03 \%$ vs. $0.91 \pm 0.05 \%, P<$ $0.05)$ and heart $(0.41 \pm 0.02 \%$ vs. $0.34 \pm 0.01 \%, P<0.05)$ were higher in mice fed with frying oil compared to those of the fresh oil group.

Serum and hepatic triglyceride, cholesterol and phospholipid level. Serum triglyceride level was lower in mice fed with dietary frying oil compared to that of mice fed fresh oil $(\mathrm{P}<0.05$, Table 1$)$. In contrast, cholesterol and phospholipid levels were higher in mice fed dietary frying oil at early ages. The data also suggested the levels of hepatic triglyceride and phospholipid was lower in mice fed with dietary frying oil compared to those of mice fed with fresh oil $(P<0.05)$.

\section{TABLE 1}

Serum and Hepatic Lipids of NZB/W F1 Mice Fed Fresh Oil or Frying Oil Diet

\begin{tabular}{lllc}
\hline Group & Triglyceride & Cholesterol & Phospholipid \\
\hline & \multicolumn{3}{c}{ serum level at 4 months of age $(\mathrm{mmol} / \mathrm{l})$} \\
Fresh oil & $0.92 \pm 0.05$ & $4.00 \pm 0.09$ & $5.00 \pm 0.20$ \\
Frying oil & $0.66 \pm 0.02^{*}$ & $4.70 \pm 0.1^{*}$ & $5.49 \pm 0.57^{*}$ \\
\hline & & $\mathrm{mg} / \mathrm{g}$ liver & \\
& & $9.29 \pm 1.56$ & $11.78 \pm 2.87$ \\
Fresh oil & $58.60 \pm 15.08$ & $5.12 \pm 2.48$ & $3.37 \pm 0.36^{*}$ \\
Frying oil & $16.79 \pm 1.77^{*}$ & & \\
\hline
\end{tabular}

Each value represents mean \pm S.E. $(* P<0.05 ;$ Student $t$ test $), n=12$.

Anti-cardiolipin level. IgM anti-cardiolipin antibody increased gradually with age, and no statistical significance was noted between the two groups (data not shown). Interestingly, at 8 months of age IgG anti-cardiolipin antibodies (Table 2) in the dietary frying oil group were significantly $(P<0.05)$ higher than in the fresh oil group.

\section{TABLE 2}

Serum Anti-cardiolipin Immunoglobulin G Levels of NZB/W Female Mice Fed Fresh Oil or Frying Oil Diet

\begin{tabular}{lcccc}
\hline \multirow{2}{*}{ Group } & \multirow{2}{*}{ 2 months } & 4 months & 6 months & 8 months \\
\hline Fresh oil & $0.002 \pm 0.002$ & $0.026 \pm 0.010$ & $0.040 \pm 0.009$ & $0.050 \pm 0.010$ \\
Frying oil & $0.024 \pm 0.017$ & $0.072 \pm 0.061$ & $0.142 \pm 0.070$ & $0.139 \pm 0.028^{*}$ \\
\hline
\end{tabular}

Each value represents mean \pm S.E. ( $* P<0.05 ;$ Student $t$ test $), n=12$.

Cytochrome P-450 content of liver tissues. The results of cytochrome P-450 content showed that the cytochrome P-450 content was higher in the livers of mice fed dietary frying oil compared to that of mice fed fresh oil $(13.04 \pm 0.54 \mathrm{nmol} / \mathrm{g}$ liver for frying oil group vs. $5.87 \pm 0.54 \mathrm{nmol} / \mathrm{g}$ liver for fresh oil group, $\mathrm{P}<0.05$ ). 
Serum estrogen level. Serum estradiol levels were higher in mice fed dietary frying oil compared to those of mice fed fresh oil (Table 3).

TABLE 3

Serum Estradiol Levels of NZB/W F1 Female Mice Fed Fresh Oil or Frying Oil Diet

\begin{tabular}{lllll}
\hline \multirow{2}{*}{ Group } & \multirow{2}{*}{2 months } & 4 months & 6 months & 8 months \\
\hline Fresh oil & $22.12 \pm 3.46$ & $35.22 \pm 5.79$ & $36.96 \pm 5.51$ & $54.27 \pm 9.10$ \\
Frying oil & $29.59 \pm 7.50$ & $62.54 \pm 11.27$ & $82.21 \pm 7.70^{*}$ & $122.37 \pm 26.50^{*}$ \\
\hline
\end{tabular}

Each value represents mean \pm S.E. $\left({ }^{*} P<0.05 ;\right.$ Student $t$ test $), n=12$.

\section{DISCUSSIQN}

Both human and murine SLE exhibits a characteristic spectrum of autoantibodies such as anti-erythrocyte, anti-DNA, anti-phospholipid antibodies. Antibodies to phospholipid are a heterogeneous group of autoantibodies found in the sera of SLE patients or murine lupus $(2,3)$. Studies suggest the level of IgG anti-cardiolipin antibodies is more closely related to the development of thrombosis and thrombocytopenia. In contrast, anti-cardiolipin antibody of IgM isotype has been linked to hemolytic anemia and livedo reticularis.

Study suggested an increase in vascular diseases only found in SLE patients with increased sera triglyceride level. It is noteworthy that serum triglyceride level in mice fed with dietary frying oil was lower compared to mice fed with dietary fresh oil. In contrast, serum cholesterol, phospholipid and anti-cardiolipin antibody levels were higher in mice fed dietary frying oil. It is speculated that increased free radicals in the environment might contribute to increased prevalence of, and an aggravated inflammatory process in, certain immunological diseases. This study showed cytochrome P-450 activity was higher in mice fed dietary frying oil compared to that of mice fed dietary fresh oil. The cytochrome P-450 activity might be closely related to the component of frying oil in the diet which is increasingly in present modern foods (6). Increased cytochrome P-450 enzyme activity may result in different degrees of lipid peroxidation and alteration of lipid metabolism. Subsequently, the changes of lipid metabolism may cause abnormal expression of the self-antigen responsible for inducing anti-phospholipid antibody.

Sex hormones, especially estrogen, have been found to affect the function of autoreactive B cells and increase autoantibody production in murine lupus (11). Moreover, recent studies showed that injection of estrogen can induce autoantibody and systemic autoimmune disease in normal mice (12). In contrast, androgen has been found to prevent the production of autoantibody and alleviate the disease severity of murine lupus (13). All this evidence suggested the possible involvement of estrogen in the pathogenesis of murine lupus. The data demonstrated higher estrogen level in mice fed dietary frying oil compared to that of mice fed dietary fresh oil. Higher estrogen level might result in increased autoantibody and subsequent pathogenic changes in autoimmune animals.

The data demonstrated dietary frying oil can influence liver cytochrome P-450 content, estrogen level and autoantibody production in autoimmune mice. It is speculated that interaction between dietary frying oil and immune regulation will become a major focus of research in future study. 


\section{REFERENCES}

1. Lin B-F, Huang C-C, Chiang B-L, Jeng S-J. (1996) Dietary fat influences Ia antigen expression, cytokine and prostaglandin $\mathrm{E} 2$ production of immune cells in autoimmune-prone NZBxNZW F1 mice. Brit J Nutr 75:711-722.

2. Lockshin MD, Druzin ML, Goei S, Qamar T, Magid MS, Janovic L, Ferenc M. Antibody to cardiolipin as a predictor of fetal distress or death in pregnant patients with systemic lupus erythematosus. N Eng J Med 1985; 313: 152-156.

3. McNeil HP, Chesterman CN, Krills SA. Immunology and clinical importance of antiphospholipid antibodies. Adv Immunol 1991; 49: 193-280.

4. Kubow, S. Routes of formation and toxic consequences of lipid oxidation products in foods . Free Radical Biol Med 1992, 12: 63-81.

5. Oarada M, Kurita N, Miyaji M, Terao K. Depression of phagocytic activity of human polymorphonuclear leukocytes by methyl linoleate hydroperoxides. J Nutr Sci Vitaminol 1991 , 37: 625-628.

6. Huang C-J, Cheung N-S, Lu V-R. Effects of deteriorated frying oil and dietary protein levels on liver microsomal enzymes in rats. J Amer Oil Chem Soc 1988; 65: 1796-1803.

7. Lin B-F, Jeng S-J, Chiang B-L, Huang C-C. Dietary fat affects lipids and anti-cardiolipin antibody levels in autoimmune-prone NZB/W F1 mice. Brit J Nutr 1997, 77:1-13.

8. Lai C-C, Lin B-F. The effects of high dietary fat and oxidized frying oil on the lipid metabolism in BALB/c mice. Nutr. Sci. J. 1997, 22: (in press)

9. Richmond N. Preparation and properties of a bacterial cholesterol oxidase from Nocardia sp. and its application to the enzymatic assay of total cholesterol in serum. Clin Chem 1973; 19 , 1350-1356.

10. Omura J, Sato R. The carbon monoxide-binding pigment of liver microsome. J Biol Chem 1964; 239: 2370-2385.

11. Cutolo M, Sulli BS, Accardo S, Masi AT. Estrogens, the immune response and autoimmunity. Clin Exp Rheumatol 1995; 13:217-226.

12. Ahmed SA, Verthelyi D. Antibodies to cardiolipin in normal C57BL/6J mice: induction by estrogen but not dihydrotestosterone. J Autoimmunity 1993; 6:265-279.

13. Roubinian JR, Talal N, Greenspan JS, Goodman JR, Siiteri K. Effect of castration and sex hormone treatment survival, anti-nucleic acid antibodies and glomerulonephritis in NZBxNZW F1 mice. J Exp Med 1978; 147:1568-1583.

Accepted for publication February 14, 1997. 